\title{
Evaluation of the School Water, Sanitation and Hygiene National Strategic Implementation Plan (2012 -2017) in Ukerewe district, north-western Tanzania
}

Joshua Patrick Ngimbwa ${ }^{1}$, Namanya Basinda ${ }^{2}$, Anthony Kapesa ${ }^{2}$, Sospatro Ngallaba ${ }^{2}$

1. Weill-School of Medicine, Catholic University of Health and Allied Sciences, P.O. Box 1464 Mwanza.

2. School of Public Health, Catholic University of Health and Allied Sciences, , P.O. Box 1464 Mwanza

$\square$ Corresponding author

E-mails

JPN: joshpatrick374@gmail.com

NB: drbasinda@yahoo.co.uk

AK: anthony1kapesa@gmail.com

SN: sngallaba@gmail.com 


\begin{abstract}
Background: Ongoing Primary and Secondary Education Development Program (PEDP \& SEDP) has led to increase in enrollment of children in schools. This created a high demand for facilities such as classroom, chairs, laboratories, latrines and water supply. Water and latrines did not receive equal attention like others. National strategic plan for School Water Sanitation and Hygiene (SWASH) 2012-2017 was to address such challenges with objectives to improve SWASH by 2017 . Hence this study aimed to evaluate the implementation of SWASH program in Ukerewe.

Methodology: A cross sectional survey was done among 42 schools in the district with 40 schools being government owned. Systematic random sampling was used and data were collected using a structured interview which was pre-tested and amended prior to conducting fieldwork. UNICEF, WASH in Schools Monitoring Package observational check-list was used to assess sanitation facilities.
\end{abstract}

Results: Findings from this study showed the latrine-hole to student ratio was 1:71 with only $31.3 \%$ of the latrines being in good clean condition and about half $(59.5 \%)$ of the schools have no facilities for washing hands. For the schools with hand washing facilities only $21.4 \%$ have an effective hand washing practice (presence of soap and water). The most common source of water used was lake water $(35.7 \%)$ with $(42.9 \%)$ having water storage facilities.

Conclusion: The study shows that most of the objectives of national strategic plan are yet to be implemented at Ukerewe. There is a need for minor repairs to complete new construction of SWASH facilities in Ukerewe.

Key words: School, Water, Sanitation and hygiene 


\section{INTRODUCTION}

Water, sanitation and hygiene related diseases persist to be one of the most substantial child health challenge worldwide(1). The diseases such as cholera malaria and diarrhea not only affect child's physical development but also school attendance and academic performance(2). This challenges of school water and sanitation are more pronounced in developing countries unlike developed world(3). According to a report by UN children's agency and its partners titled "raising clean hands" in sixty countries in the developing world more than half of primary schools have no suitable water facilities and nearly two-thirds lack adequate sanitation(3).

In Tanzania there is an increasing in tolls of communicable diseases such as diarrhea and stunting due to poor sanitation and unhygienic behavior practices(4). The study conducted by Netherlands Development Organization (SNV), Water Aid and UNICEF in 2009 in 16 districts covering 2697 schools in Tanzania mainland. About $6 \%$ of the schools had no latrines, $84 \%$ had no hand washing facilities and $86 \%$ had no water for hand washing(4). Through encouraging movements that spearhead simple hygiene practices like washing hands with soap can reduce the incidence of diarrhea by an estimated 47 per cent while use of suitable sanitation can lessen cases of diarrhea by an estimated 36 per cent(5). Presence of unsatisfactory WASH facilities in homes, schools and health centers become breeding grounds for diseases that cause child mortality and morbidity. Girls, children with disabilities and children living in rural areas are the most affected(5).

Due to existing programs in primary and secondary school such as Primary and Secondary Education Development Program (PEDP \& SEDP) which aimed at delivering sustain-able, universal basic education of good quality through abolishing of primary school fees for (PEDP), increase in quality of education and compulsory enrollment at the age of seven(6). This led to an increase in enrollment of children in schools. This increases led to a high demand for facilities 
such as classroom chairs laboratories latrines and water supply. Unfortunately water and latrines did not increase in equal proportion with the increased number of students.

National strategic plan for school water sanitation and hygiene (SWASH) 2012-2017 was brought forward to address the challenges recognized by the government and other stake-holders on insufficiency of WASH services in schools(7). The initiative took into account different measures to improve wash situation in schools and with a target of increasing WASH facilities by $50 \%$ in schools by 2016/2017(7, 8). Some of the strategic plans brought forward were. "(i) Awareness and capacity building this include establishment of awareness to teachers and pupils about issues concerning WASH, (ii) Sanitation facilities such as latrines like pour flush ventilation, improved pit latrine and ecologic latrines. Hygiene facilities include hand washing facilities and changing room for girls, were as well planned to be built. Additionally, cross-cutting issues took into concern gender and disabilities of school children to ensure equity and inclusion during WASH execution, (iii) Infrastructure development and maintenance, major infrastructure included water facilities namely; tap water, shallow well, spring holes, rainwater harvesting, and bore holes".

The National Strategy for Growth and Reduction of Poverty II (NSGRP II) target for school sanitation necessitates all schools to meet the minimum standard of one latrine for every 20 girls and one latrine for every 25 boys, as stipulated in education policies (URT, 200c). Though initially this would be 40-50 in order to ease the urgent demands(9). Goal six of the new SGDs emphasizes the need for "access to adequate and equitable sanitation and hygiene for all"(10). In Tanzania, there are limited data on the performance of the SWASH program in schools(11-13). This study therefore aims at evaluating the implementation of SWASH program in Ukerewe district NorthWestern Tanzania. 


\section{MATERIALS AND METHODS}

\section{Study area}

Ukerewe district makes one of the seven districts of Mwanza region of Tanzania. It has 24 wards with a total population of 345,147 by 2012 national census and natives are mainly Kerewe(14). It is the largest island in Lake Victoria with an area of approximately 530 square $\mathrm{km}$. The main source of water are dug wells and the surrounding Lake Victoria. Ukerewe District has 123 primary schools and 25 secondary schools(15).

\section{Study design and Sampling}

This was a cross-sectional study done on September 2019. From a list of 148 schools a total of 42 schools were sampled in line with the WHO and UNICEF guideline for small area health system studies(16). Through observation of the WHO and UNICEF guidelines it renders my study sample valid for representation of the whole population. From the selected 42 schools 33 were primary schools with 17 being primary schools only and 16 having both pre and primary schools, about 9 secondary schools were sampled for the study in a period of 1 month from $1^{\text {st }}$ September to $30^{\text {th }}$ September 2019, below table 1 shows some demographic information about the study sample.

Systematic random sampling technique was used to obtain the participating schools, where a list of schools one for primary schools and another for secondary at Ukerewe was generated and a systematic sampling technique was used whereby after every three schools a school was picked. All schools at Ukerewe district were included for the study while schools that did not consent were excluded from the study. Consent was obtained from the head teachers or assigned teacher before the face to face interview. All of the individuals approached agreed to participate (response rate was $100 \%)$. 
Table 1: Demographic information data

\begin{tabular}{|c|c|c|c|}
\hline Variable & $\begin{array}{l}\text { Primary Schools } \\
\mathrm{n}(\%)\end{array}$ & $\begin{array}{l}\text { Secondary Schools } \\
\mathrm{n}(\%)\end{array}$ & Total \\
\hline Male students & $15929(83 \%)$ & $3224(17 \%)$ & 19153 \\
\hline Female students & $16349(86 \%)$ & $2563(14 \%)$ & 18912 \\
\hline $\begin{array}{l}\text { Students with } \\
\text { disability }\end{array}$ & $(91.5 \%)$ & $9 \quad(8.5 \%)$ & 107 \\
\hline Teachers & $411 \quad(68 \%)$ & $194 \quad(32 \%)$ & 605 \\
\hline
\end{tabular}

\section{Data Collection and Analysis}

The research was conducted on the respective school grounds and data were collected using a structured interview adopted from the Poverty Diagnostic of Water Supply, Sanitation and Hygiene Sector in Tajikistan school survey questionnaire after being contracted by the World Bank. The questionnaire was pre-tested in schools found at Nyamagana district in Mwanza, Tanzania and amended by a team of public health specialists at the Catholic University of Health and Allied Science prior to conducting fieldwork to improve its efficacy in collecting data in the respective setting. Research assistants were individuals trained in research from Catholic University of Health and Allied Science this was to ensure consistency and reliability of data collection. The survey instrument was initially designed in English, translated to Kiswahili and then translated back to English by another translator to ensure that the translated version captured the questions correctly. The interviews were conducted in Kiswahili which was the primary language of the interviewer and interviewees. 
The sanitation facilities were assessed using a checklist adopted from the UNICEF, WASH in Schools Monitoring Package(17).

Data entry, processing and analysis was done through IBM SPSS statistics 20 computer program. Categorical data such as sex and level of cleanliness of a certain facility were tabulated and frequencies and percentages were computed by plotting histograms. 


\section{RESULTS}

\section{Demographic information}

The study was conducted on 42 school in Ukerewe district in September 2019. Where by 33 were primary schools with 17 being primary schools only and 16 having both pre and primary schools, about 9 were secondary schools. 40 out of the 42 schools were government owned schools while 2 were faith-based organization schools. The primary schools under the study had an enrollment of 32172 students and secondary schools had an enrollment of 5785 students. The total number of primary school teachers was 411 and that of secondary school teachers was 194 . That sums up to a ratio of 1 teacher to a population of 78 students for primary schools and 29 students for secondary schools. Table 1 below gives a highlight on various demographic information.

Table 1: Demographic information data

\begin{tabular}{|c|c|c|c|}
\hline Variable & $\begin{array}{c}\text { Primary Schools } \\
\mathrm{n}(\%)\end{array}$ & $\begin{array}{c}\text { Secondary Schools } \\
\mathrm{n}(\%)\end{array}$ & Total \\
\hline Male students & $15929(83 \%)$ & $3224(17 \%)$ & 19153 \\
\hline Female students & $16349(86 \%)$ & $2563(14 \%)$ & 18912 \\
\hline Students with disability & $(91.5 \%)$ & $(8.5 \%)$ & 107 \\
\hline Teachers & $(68 \%)$ & $194 \quad(32 \%)$ & 605 \\
\hline
\end{tabular}

\section{Crosscutting issues (gender consideration and facilities to students with disabilities)}

The study findings show that around 93\% (39/42) had separate toilets for both male and female students. About 45\% (19/42) schools had toilets for teachers with all of them being separated for male and females. Only 25\% (12/42) of the schools had facilities for disabled children. Further none of the schools had changing rooms for the ladies during menstruation. 


\section{Availability of Water Source}

About $35.7 \%$ (15/42) schools used water from the Lake Victoria, where by students had to go fetch water from the lake for various school uses and only 7 schools harvested rain water. Regarding water storage facilities, 43\% (19/42) of the schools had water storage facilities in the school environment. For the schools that managed to collect water or store it only $42.9 \%(19 / 42)$ treated water for consumption. See table 2.

Table 2: Sources of water used by schools at Ukerewe district

\begin{tabular}{|c|c|c|c|}
\hline Water source & $\begin{array}{l}\text { Number of primary } \\
\text { schools }\end{array}$ & $\begin{array}{l}\text { Number of secondary } \\
\text { schools }\end{array}$ & Total \\
\hline $\begin{array}{l}\text { borehole well with } \\
\text { pump }\end{array}$ & 1 & 0 & 1 \\
\hline protected dug well & 2 & 1 & 3 \\
\hline protected spring well & 1 & 0 & 1 \\
\hline rain water & 4 & 3 & 7 \\
\hline unprotected dug well & 1 & 0 & 1 \\
\hline Lake & 12 & 3 & 15 \\
\hline tap water & 6 & 2 & 8 \\
\hline $\begin{array}{l}\text { unprotected shallow } \\
\text { natural well }\end{array}$ & 6 & 0 & 6 \\
\hline
\end{tabular}




\section{Sanitation}

The ratio of number of holes to male students was 1 hole for 70 students and that of female students was 1 hole for 71 students. Also the number of toilet holes per school was 12 latrines per school.

Most schools used flushing toilets as a common defecation facility $31 \%$ (13/42). See figure 1 .

From the study about $73 \%$ (31/42) of the schools had no any cleaning utensils such as brooms mopes cleaning soaps. Few facilities, $11.9 \%$ (5/42) were in good condition, with no structural damage such as the toilet seat or waste collection apparatuses that could compromise sanitation management or students health when using the facilities. Around 61.9\% (26/42) of the sanitation facilities were in poor condition where the structural damage was present but minor and could be modified with simple renovations. Some facilities (11/42) require complete reconstruction.

\section{Figure 1: Common Defecation Facilities Used by the Schools}

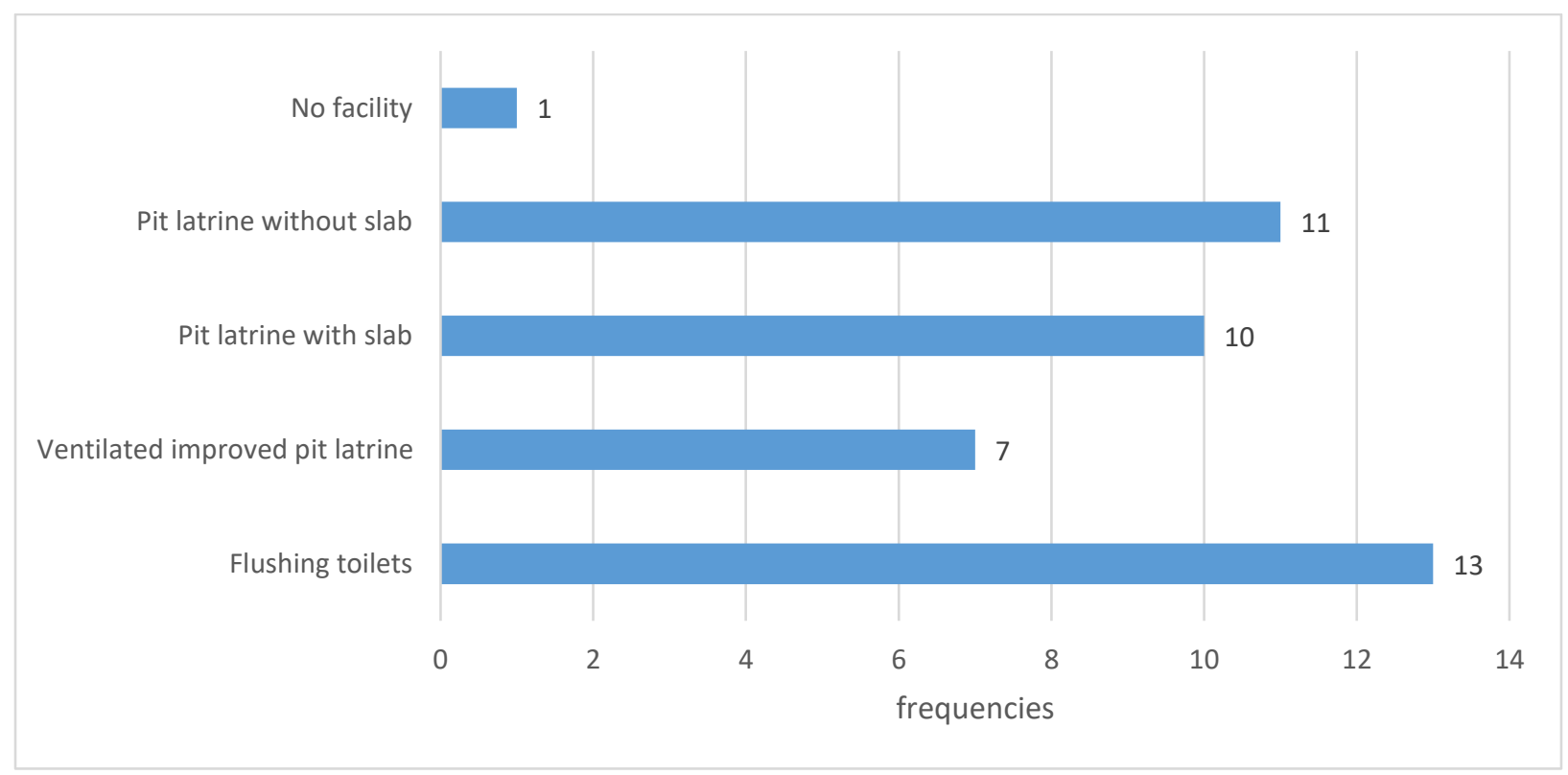




\section{Hygiene}

About 59\% (25/42) of the schools did not provide any facility for washing hands after using the toilets. For those that provided facilities for washing hands after using the toilets, majority of their hand washing facilities were not of good effectiveness for hand washing practices (provided water without soap for cleaning hands or had hand washing utensils but had no water in them).

\section{Awareness and capacity building about WASH}

None of the 42 schools had Information, Education Communication (IEC) materials such as signs, stickers or posters for WASH. Majority of the schools 81\% (34/42) schools have school gathering, but these are rarely used for raising awareness and capacity building on WASH; the respondents claimed, the gathering were for academic purposes, and, none of the schools have WASH committees in place. 


\section{DISCUSSION}

Findings from this study shows that about $93 \%$ of the schools have separate toilets for both male and female students. However the toilets were not completely detached hence not completely considered as gender specific. Studies show that absence of gender specific toilets may lead to poor educational aftermaths and school drop outs especially to girls(18). Moreover there is lack of user friendly facilities for disabled children's (only $25 \%$ of the schools having facilities for disabled children). This makes the vulnerable group feel secluded in schools causing a significant impact in enrolment absenteeism and lack of pupils safety(19, 20). As shown in a randomised controlled trial conducted in Kenya where the presence of an appropriate WASH environment increased attendance by 60\%(19). None of the schools had changing facilities for girls during menstruation. This serves as a problem since it hinders menstrual hygiene and causes depression among young girls during menstruation(21). This differs from a study done in Kenya and Malawi where only $10 \%$ of the schools in Kenya provided sanitary pads to students and had changing room(22). However this was made possible by aids from various NGO's(22). Provision of clean and safe place for menstrual hygiene in schools is very important as lack of such facilities can lead to depression during menstrual period due to failure to manage their periods. This is still a big problem among school girls(12, 23).

The study has shown that most school have one source of water, the lake Victoria. However distance from the lake and lack of storage facility for water continue to be a challenge in having constant supply of water. A study done in Cambodia shows that there is a significant association between the provision of supplementary water in the classroom and reduction absenteeism rates(24). Also our study differs from a study done in Nyanza Kenya where all the schools in the study had alternative water storage facilities and $78 \%$ of the schools in the study provided water 
for their students(22). This difference might be due to the small sample size used by the study done in Kenya where it consisted of only nine schools while in this study 42 schools were used for the study.

Moreover the study shows that the ratio of number of holes to students in male was 1 hole for 70 students and that of female was 1 hole for 71 students. The recommended standard by WHO is 1 hole for 25 boys and 1 hole for 20 girls. Studies done have shown that having additional latrines helps to reduce absence, increase enrolment and decreases diarrheal illness (25). In comparison from study that was done in Kenya where the average latrine to students ration was 1:36 this was achieved after implementation of national sanitation campaign(26).

From the study $31 \%$ (13/42) of schools used flushed toilets as a common defecation facility. The use of flushed toilets is complicated by water scarcity in the area. This has led to most of the school toilets being in poor conditions. This is because cleanliness could not be maintained as most of students defecated without flushing. Most of school with flush toilet were in a poorer condition compared to schools with pit latrines toilets, as facilities to flush were not working or no water. In some schools there were no toilets and students defecated in the bushes or areas close to the school environment. This leads to increase in diarrhoeal illnesses and students bearing much of the burden of soil-transmitted helminthic morbidity. Inadequate sanitation can lead to a number of health problems, including stunted growth and even death(25).

The situation above is further complicated by the fact that about $73 \%$ of the schools had no cleaning utensils. In most occasions students were required to bring their own cleaning utensils. Also majority of the facilities were constructed long time ago (some in 1960's) hence needed major renovation to make them suitable for use. 
In additional to the above situation around half of the schools (59\%) did not provide any facilities for washing hands, the ones with hand washing facilities only $21.4 \%$ had effective hand washing practices (presence of soap and water). Other facilities provided water without soap for cleaning hands and some had hand washing utensils but had no water in them. The national strategic plan goals were to ensure adequate provisions of hygiene facilities such as effective hand washing stations in each schools and either in the toilets or immediate out of the toilets(7). Since studies show that Hand hygiene at schools and within our communities plays an essential role in helping to reduce the spread of infectious diseases(27). A study done in 2018 in Ghana showed that $33 \%$ of schools had students washing their hands in a shared receptacle (bowl), $24 \%$ had students using a single cotton towel to dry hands after hand washing, and only $16 \%$ of schools had a functional water facility(28). Furthermore none of schools under the study had Information, Education and Communication materials (IEC) like signs, stickers or posters that acted on raising awareness about sanitation and hygiene Most of the schools had social gatherings however respondents claimed the gathering were for academic purposes rather than raising awareness about WASH. Involvement of parents in SWASH projects helps financial contributions hence creating sustainable facilities for long term use(29). None of the schools having WASH committees. Presence of WASH committees involving student's teachers and parents contribute positively by tackling various WASH challenges in schools and help develop of WASH facilities in schools for long term sustainability(29). 


\section{CONCULUSION}

Apart from the inconsistent and/or lack of water sources in schools, the students per hole ratio is far behind WHO standards. In general the area under study lack adequate implementation of WASH requirements contributing to a slow achievement of the implementation of the National strategic plan for SWASH 2012-2017 strategies in Tanzania. However to overcome these challenges investment in SWASH facilities needs to be made in Schools in Ukerewe district.

\section{List of abbreviations}

CFS - Child Friendly Schools

MKUKUTA - National Strategy for Growth and Poverty Reduction Tanzania

PEP - Primary School Development Plan

SEDP - Secondary School Development Plan

SNV - Netherlands Development Organization

SWASH - School Water Sanitation and Hygiene

UN - United Nations

UNICEF - United Nations International Children Emergency Fund

\section{DECLARATIONS}

\section{Acknowledgements}

The authors acknowledge the Catholic University of Health and Allied Science for giving us support with various research materials including questionnaires and personnel who helped with data collection and analysis. The Ukerewe District Medical Officer, Ukerewe District for granting 
us the permission to conduct our survey and giving us full support needed to complete our study successfully.

\section{Ethical Approval}

Ethical approval was obtained from the Joint Catholic of Health and Allied Sciences and Bugando Medical Centre Research Ethics and Review Committee with registration number 1369/2019. Permission to conduct the research in Mwanza Region and Ukerewe District was obtained from the offices of the Regional and District Commissioners. Written informed consent was obtained from each participant. The support from the government officials is among contributing factor to the successful of $100 \%$ response rate. The investigators also obtained the support of the interviewees, proper introduction by the study team by visiting and introducing the purpose and importance of the study to the entire sampled population also contributed to achieving $100 \%$ response rate.

\section{Consent for Publication}

Not applicable. All results are presented without individual's identification.

\section{Availability of data and materials}

Data from this study are available within the manuscript provided in quotations and

observation reports. However, data set (recordings, transcriptions and notes) used and

analysed during the current study are available from the corresponding author on reasonable

request and with permission from the Catholic University of Health and Allied Sciences and

Bugando Teaching and Consultant Hospital joint ethical committee 


\section{Competing interests.}

The authors declare that they have no competing interests

\section{Funding.}

Funding for this study was obtained from personal sources throughout the s

\section{Authors' contribution:}

JPN, NB designed the study. JPN collected data. All authors drafted the

manuscript and critically reviewed and provided final approval for publication.

\section{REFERENCE}

1. WHO. Water for health taking charge 2001 [Available from: https://www.who.int/water sanitation health/takingcharge.html.

2. Trinies V, Garn J, Chang H, Freeman M. The Impact of a School-Based Water, Sanitation, and Hygiene Program on Absenteeism, Diarrhea, and Respiratory Infection: A Matched-Control Trial in Mali. American Journal of Tropical Medicine and Hygiene. 2016;94.

3. UNICEF. Raising clean hands 2010 [Available from: https://www.unicef.org/media/files/raisingcleanhands 2010.pdf.

4. CN R. SWASH Consolidated Nation Mapping Report 2010 [Available from: http://washinschoolsmapping.com/wengine/wpcontent/uploads/2015/10/Tanzania School Wash Report.pdf.

5. UNICEF. Water, sanitation and hygiene [Available from: https://www.unicef.org/tanzania/whatwe-do/wash.

6. Gaddis I, Hoogeveen J. Primary Education in Mainland Tanzania: What Do the Data Tell Us? 2015. p. 7-25.

7. moeav t. National Stratetigic plan forschool water sanitation and hygiene 2012-2017 2012 [Available

from:

http://www.unesco.org/education/edurights/media/docs/39d043c2367b728dd6580cc173bb4ce26e2f8 Of7.pdf.

8. Moesa t. NATIONAL GUIDELINE FOR WATER, SANITATION AND HYGIENE FOR TANZANIA SCHOOLS 2016 [Available from: http://www.moe.go.tz/index.php/en/component/idownloads/send/36-guidelinesmiongozo/227-swash-guideline-2016.s.

9. AFFAIRS MOFAE. national strategy for poverty reduction ii 2010 [Available from: https://www.international.gc.ca/development-developpement/assets/pdfs/countries-pays/NATIONALSTRATEGY-FOR-GROWTH-AND-REDUCTION-OF-POVERTY-TANZANIA.PDF.

10. UNDP. sustainable development goals 2015 [Available from: https://www.undp.org/content/undp/en/home/sustainable-development-goals.html. 
11. f k. water sanitation and hygiene in tanzania : asses policy trends and financing 2017 [Available from: http://www.thdr.or.tz/docs/THDR2017BP-11.pdf.

12. $\mathrm{s} \mathrm{m}$. Where the Education System and Women's Bodies Collide: The Impact of Girls' Experiences of Menstruation and Schooling in Tanzania. Journal of Adolescence. 2010;33(4):521-529 doi:101016/jadolescence200903008.

13. R T. water sanitation and hygiene 2019 [Available from: https://raleightanzania.org/ourwork/programmes-and-projects/water-sanitation-hygiene/.

14. Population Statistics C MaLI. Ukerewe (District, Tanzania) - Population Statistics, Charts, Map and Location [Internet 2018 [Available from: http://www.citypopulation.de/php/tanzaniaadmin.php?adm2id=1901.

15. haki-elimu. ukerewe district 2012 [Available from: http://hakielimu.org/files/schools/Ukerewe\%20District.pdf.

16. UNICEF W U. guidlines for mornitoring the availabiltiy and use of obstetric services. newyork. 2007.

17. UNICEF. WASH in Schools Monitoring Package 2011 [Available from: https://www.unicef.org/wash/schools/files/WASH in Schools Monitoring Package English.pdf.

18. Isolde Birdthistle CfM, Reproductive \& Child Health (MARCH), London School of Hygiene \& Tropical Medicine (LSHTM) What impact does the provision of separate toilets for girls at schools have on their primary and secondary school enrolment, attendance and completion 2011 [Available from: https://www.pseau.org/outils/ouvrages/Ishtm what is the impact of separate toilets for girls at s chools on girls educational outcomes a systematic review of the evidence 2011.pdf.

19. Antwi-Agyei P MA, Seleman A, Tenu F, Kuiwite T, Kiberiti S, et al. Water, sanitation and hygiene (WASH) in schools: results from a process evaluation of the National Sanitation Campaign in Tanzania. 2017;7(1):140-50.

20. anthony Pj. Segregation Hurts 2013 [Available from: https://books.google.co.tz/books?id=8WdIAAAAQBAJ\&pg=PA26\&lpg=PA26\&dq=lack+of+user+friendly+t oilets+for+disabled+contribute+to+absenteeism+in+school\&source=bl\&ots=3iRsOsQWG1\&sig=ACfU3U3 hYtRalr3ZnWcoE1MnGVIVYgk-tA\&hl=en\&sa=X\&ved=2ahUKEwiU9d-85sDoAhVBtXEKHXHD0sQ6AEwFnoECAoQAQ\#v=onepage\&q=lack\%20of\%20user\%20friendly\%20toilets\%20for\%20disabled \%20contribute\%20to\%20absenteeism\%20in\%20school\&f=false.

21. Sommer M HJ, Nathanson C, Parker RG. Comfortably, safely, and without shame: defining menstrual hygiene management as a public health issue. Am J Public Health. 2015;105:1302-11.

22. CE OR. knowledge and practices of students and their parents: Nyanza Province, western Kenya. cambridge core. 2006;2006;136(1).

23. Grant M, Lloyd C, Mensch B. Menstruation and school absenteeism: evidence from rural Malawi. Comparative education review. 2013;57(2):260-84.

24. F.b HPRaRHaYMbLHbLCcHPdLCeJ. Impact of the Provision of Safe Drinking Water on School Absence Rates in Cambodia: A Quasi-Experimental Study 2015 [Available from: https://www.karger.com/Article/FullText/381244.

25. Garn J, Caruso B, Drews-Botsch C, Kramer M, Brumback B, Rheingans R, et al. Factors Associated With Pupil Toilet Use in Kenyan Primary Schools. International journal of environmental research and public health. 2014;11:9694-711.

26. Alexander KT, Oduor C, Nyothach E, Laserson KF, Amek N, Eleveld A, et al. Water, sanitation and hygiene conditions in Kenyan rural schools: are schools meeting the needs of menstruating girls? Water. 2014;6(5):1453-66.

27. Boshell P. The importance of hand hygeine at home and at school 2017 [Available from: https://info.debgroup.com/blog/hand-hygiene-at-home-and-school. 
28. Appiah-Brempong E HM, Newton S, Gulis G. Examining school-based hygiene facilities: a quantitative assessment in a Ghanaian municipality. BMC Public Health

2018; 2018;18(1):581.

29. UNICEF. Water, Sanitation and Hygiene (WASH) in Schools 2012 [Available from: https://www.unicef.org/publications/files/CFS WASH E web.pdf. 